\title{
Comunidades que sustentam a agricultura (CSAs): produção orgânica integrada e escoamento de produtos
}

\author{
Pedro Canuto Macedo Sales ${ }^{1}$ \\ João Paulo Guimarães Soares ${ }^{2}$ \\ Ana Maria Resende Junqueira ${ }^{3}$ \\ Maria Julia Pantoja ${ }^{4}$
}

Submissão: 30/09/2021

Aceite: $29 / 10 / 2021$

\begin{abstract}
Resumo
A produção alternativa de alimentos, e o escoamento por meio das cadeias curtas de comercialização tem se tornado uma realidade do produtor rural, sobretudo no período de pandemia. Nesse sentido tem se destacado as Comunidades que sustentam a agricultura, como um sistema de escoamento de alimentos orgânicos por meio da parceria direta entre consumidores e produtores. Nesse conjunto de fatores a criação de animais se mostra importante, sendo parte integrante dos sistemas de produção orgânicos, contribuindo com a manutenção da biodiversidade e a recuperação do solo, como também para o fornecimento de produtos orgânicos de origem animal. Dessa forma buscou-se nesse estudo, caracterizar os sistemas produtivos integrados dos agricultores familiares do assentamento Nova Camapuã-DF e analisar sua contribuição visando a organização de modelos de produção e comercialização de produtos orgânicos. Para tanto foi aplicado um questionário abordando todos os objetivos do estudo, a 16 produtores do assentamento que se disponibilizaram a fazer parte da pesquisa, utilizando-se como técnicas de análise dos dados, a análise estatística e de conteúdo. Os resultados apontaram que a criação de animais pode contribuir para produção de maneira orgânica e a criação de CSAs, uma vez que além de contribuir através do reaproveitamento de resíduos se mostram como uma alternativa para a geração de renda aos estabelecimentos, apresentando também ganhos no aspecto das relações sociais. Percebeu-se que a organização de CSA pode contribuir para a melhoria das condições dos produtores no que se refere a capacidade de investimento, escoamento de produtos e melhorias das condições de vida.
\end{abstract}

Palavras-chave: Produção Orgânica. Sistemas Integrados. Agricultura familiar. Produção Animal. Comunidade que Sustenta a Agricultura.

\section{Community supported agriculture: integrated organic production and product disposal}

\begin{abstract}
The Alternative food production and flow through short marketing chains has become a reality of rural producers, especially in the pandemic period. In this sense, the communities that support agriculture, as a system of organic food flow through the direct partnership between consumers and producers, have been highlighted. In this set of factors, animal husbandry is important, being an integral part of organic production systems, contributing to the maintenance of biodiversity and soil recovery, as well as to the supply of organic products of animal origin. Thus, this study aimed to characterize the integrated production systems of family farmers in the Nova Camapuã-DF settlement and analyze its contribution aiming at the organization of models of production and commercialization of organic products. For this, a questionnaire was applied addressing all the objectives of the study, to 16 producers of the settlement who were made available to be part of the research, using statistical and content
\end{abstract}

\footnotetext{
${ }^{1}$ Mestrado em Agronegócios (PROPAGA-UnB). E-mail: pcsalesadm@gmail.com.

${ }^{2}$ Doutorado em Zootecnia (UNESP). Pesquisador da Embrapa Cerrados - Planaltina/DF. Professor do Programa de Pós-Graduação em Agronegócio (PROPAGA-UnB). E-mail: jp.soares@embrapa.br.

${ }^{3}$ Doutorado em Produção Vegetal (University of Wales, Grã-Bretanha). Pós-Doutorado em Gestão da Qualidade na Produção Agrícola (University of Queensland, Austrália). Professora do Programa de Pós-Graduação em Agronegócio (PROPAGA-UnB). E-mail: anajunqueiraunb@gmail.com.

${ }^{4}$ Doutorado em Psicologia Organizacional e do Trabalho (UnB). Professora do Programa de Pós-Graduação em Agronegócio (PROPAGA-UnB). E-mail: jpantoja@unb.br.
} 
analysis as data analysis techniques. The results showed that animal husbandry can contribute to organic production and the creation of CSAs, since in addition to contributing through the reuse of waste, they are an alternative for generating income to establishments, also showing gains in the aspect of social relations. It was noticed that the organization of CSA can contribute to the improvement of the conditions of producers with regard to investment capacity, product disposal and improvements in living conditions.

Keywords: Organic production. Integrated systems. Family farming. Animal production. Community Supported Agriculture

\section{Introdução}

A produção de alimentos sempre esteve como uma das principais atividades desenvolvidas pelo ser humano durante toda a história de sua existência, uma vez que é um elemento essencial para sua sobrevivência. Com isso diferentes técnicas foram desenvolvidas e aprimoradas com a finalidade de se obter alimentos em quantidade necessária para toda a população.

De acordo com Assis e Romeiro (2002) as primeiras tecnologias agrícolas implementadas foram a rotação de culturas e a integração da produção de animais e plantas, de forma a não agredir o meio ambiente e conseguir superar suas limitações ecológicas tendo como ferramentas as próprias leis da natureza. Contudo, essa realidade passou a se modificar a partir do século XIX, por meio da implementação da química agrícola em que foram difundidos novos modelos de produção por meio de adubos químicos, uso excessivo de insumos químicos, agrotóxicos, variedades de plantas geneticamente modificadas e a mecanização (ASSIS; ROMEIRO, 2002) (ALTIERI, 2004), (ABREU et al., 2012).

Em resposta a essa realidade a agricultura orgânica surge descrita por Sir Albert Howard, botânico inglês, no século XX e em seguida estimuladas também a criação de diversas correntes de agriculturas alternativas ao sistema convencional, com destaque a agricultura orgânica e de base ecológica, por serem as mais utilizadas. Com o passar dos anos os consumidores se mostram cada vez mais adeptos para o consumo de alimentos orgânicos conforme apontam Mandolesi et al. (2015), Nicholas et al. (2014), Bainbridge et al. (2017), Rey (2015), Liang et al. (2017) por se tratar de modos de produção respeitosos a saúde humana, a sustentabilidade ambiental e bem-estar dos animais.

Impulsionado por essas mudanças ocorre também o fortalecimento das cadeias curtas de comercialização de alimentos, tendo como principais adeptos os agricultores familiares. De acordo com Hatanaka, Bain e Busch (2005) devido a vários escândalos alimentares, como por exemplo, o trabalho infantil, o uso indiscriminado de agrotóxicos, a contaminação de alimentos e os maus tratos ao animais, os consumidores perderam a confiança em sistemas 
produtivos em massa. Esses fatos tem favorecido o aumento de pessoas que buscam o contato direto com os agricultores para adquirir seus alimentos, pois dessa forma possuem o conhecimento das técnicas utilizadas para produção, bem como permite uma maior interação e cooperação entre os agricultores e consumidores sendo essa aproximação vantajosa para ambas as partes Hatanaka, Bain e Busch (2005), Darolt et al. (2016).

Dentre as formas de comercialização de alimentos locais Brown e Miller (2008), destacam a Comunidade que Sustenta a Agricultura (CSA) como uma das que mais tem se desenvolvido em diversas partes do mundo. Provavelmente a razão para isto tenha sido o fato de que esta modalidade permite uma maior interação entre agricultores e consumidores.

Cabe ainda destacar a importância da criação de animais, que de acordo com Figueiredo e Soares (2012), são parte integrante dos sistemas orgânicos de produção, sendo comprovada a eficiência da integração de animais e vegetais como uma forma de favorecer a biodiversidade e a recuperação dos nutrientes do solo. Porém, Soares, Neves e Carvalho (2014) destacam que a oferta desses produtos ainda se encontra em uma fase muito insipiente, apesar de, por outro lado, a procura por produtos orgânicos de origem animal se encontrar aquecida.

Nessa perspectiva, o objetivo deste trabalho é caracterizar a realidade da criação de animais e seus subprodutos, do assentamento Nova Camapuã-DF, e analisar de que forma a integração da produção animal pode contribuir para a implementação dos sistemas integrados de produção e comercialização.

\section{Agricultura orgânica e de base ecológica no mundo e no Brasil}

O surgimento da agricultura orgânica ocorreu entre as décadas de 1920 e1940, período em que o agrônomo inglês Sir Albert Howard realizou estudos sobre o solo e o papel dos microrganismos para manutenção do solo vivo por meio da adubação orgânica. Os primeiros experimentos foram realizados na Índia e na Europa, posteriormente se expandindo para outros países e continentes, levando ao desenvolvimento de um novo modelo de agricultura difundido como um modo alternativo de produção. Através dessa expansão foi criada, em 1972, a Federação Internacional dos Movimentos de Agricultura Orgânica (IFOAM), sendo essa a responsável por implantar um sistema visando garantir a qualidade dos produtos orgânicos para seus consumidores passando a estabelecer padrões internacionais de 
produção e criando o Sistema de Garantia orgânica (Organic Guarantee System - OGS), (HELENA et al., 2017).

A agricultura orgânica tem apresentado a cada ano expressivas taxas de crescimento em todo o mundo. De acordo com Willer e Lernoud (2019) no levantamento realizado pelo Research Institute of Organic Agriculture (FIBL), em parceria com a IFOAM, a agricultura orgânica se encontra no seu maior estágio de desenvolvimento desde que se iniciaram as pesquisas do FIBL há 20 anos atrás, contando com 70 milhões de hectares e apresentando crescimento de mercado em todo o mundo, o que culminou para alcançar a marca de 97 bilhões de dólares cerca de 90 bilhões de euros, sendo estes os maiores níveis já registrados.

A agricultura orgânica está presente em 181 países, com um total de 2,9 milhões de produtores em todo o mundo. Dentre os países mais representativos nesse mercado encontram-se os Estados Unidos atual líder com 40 bilhões de euros, em segundo lugar a Alemanha com 10 bilhões, vindo logo após a França com 7,9 bilhões e a China 7,6 bilhões (WILLER E LERNOUD, 2019).

De acordo com os dados de Willer e Lernoud (2019) na América Latina e Caribe onde - Brasil se encontra, foram registrados cerca de 460 mil produtores e mais de 8 milhões de hectares sob manejo orgânico, constituindo $11 \%$ dos produtores orgânicos do mundo e 1.1 \% das terras. No que se refere a quantidade de terras sob manejo orgânico na América Latina e Caribe, os países líderes foram a Argentina (3,4 milhões de hectares), o Uruguai (1,9 milhão de hectares) e o Brasil (1,1 milhão de hectares). Sendo importante destacar que ainda segundo os mesmos autores que o Brasil possui atualmente 15.030 mil produtores orgânicos correspondendo a aproximadamente 3.3\% dos produtores da América Latina e Caribe.

Willer e Lernoud (2019) destacam que o mercado de produtos orgânicos da América Latina e Caribe mostra-se com alta demanda nos mercados internacionais, como também no mercado interno. O Brasil é o país com o maior mercado orgânico do continente, sendo está demanda originaria da crescente procura por alimentos nutritivos e saudáveis.

Destaca-se ainda os países México, Brasil, Chile, Paraguai, Bolívia e Argentina que possuem o selo nacional de produto orgânico, com atenção especial para as suas legislações que possuem a combinação do componente social, diferencial este que contribui para o surgimento de oportunidades para milhares de pequenos produtores com destaque aos Sistemas de Garantia Participativa e Organizações de Controle Social (WILLER; LERNOUD, 2019). 


\subsection{Produção orgânica de origem animal no mundo e no Brasil}

Os sistemas de produção animal constituem parte integrante dos sistemas orgânicos, uma vez que a produção orgânica visa a diversidade e ambientes próximos do ecossistema natural, sendo importante a participação integrada de animais e vegetais Em conjunto, esses sistemas contribuem para o equilíbrio ambiental e a manutenção da biodiversidade do solo, favorecendo a suplementação de nutrientes e recursos naturais (FIGUEIREDO; SOARES, 2012). Apesar da agricultura orgânica ser mais frequentemente ligada, a frutas, vegetais e cereais, a produção de origem animal também está presente em todo o mundo, ganhando a cada dia mais notoriedade no mercado (WILLER E LERNOUD, 2019).

Assim como os produtos vegetais os produtos de origem animal têm ganhado maior destaque devido ao contínuo aumento de consumidores preocupados com a saúde, questões ambientais e sociais, acrescendo-se ainda para essa classe de produtos as questões relacionadas ao tratamento e bem-estar dos animais. Na produção orgânica é priorizado o manejo racional, tratamento adequado e ambientes favoráveis de acordo com cada espécie animal visando a prevenção de doenças em busca de animais adaptados ao ambiente e imunologicamente fortes, livres de fome, sede, medo e cativeiro, garantindo-lhes assim uma vida mais próxima possível do natural. Práticas que buscam a redução da utilização de medicamentos químicos, como também a não utilização de pesticidas para controle de parasitas e insetos, sendo essas algumas características que ao longo dos anos tem chamado cada vez mais a atenção de mais consumidores para a compra desses produtos. (RIBEIRO; ARANDAS, 2018).

Em geral as análises mostram que os sistemas orgânicos de produção animal são viáveis economicamente, existindo uma diversidade de arranjos produtivos, maiores ganhos por se tratar de produtos diferenciados, além de contribuir para a produção vegetal através de adubos naturais. Tosetto, Cardoso e Furtado (2013) elencam pelo menos três fatores positivos que demostram a importância da presença dos animais nos sistemas produtivos:

(i) Produção de esterco: O esterco produzido na propriedade contribui para a garantia da sustentabilidade orgânica e econômica do sistema, pois reduz ou elimina a necessidade de comprar adubos químicos ou mesmo esterco de outras fontes que podem conter vestígios de agrotóxicos; (ii) Diversidade na produção: Os produtos de origem animal são ricos em proteínas e podem contribuir com a segurança alimentar da família e gerar renda através da venda do excedente de produtos, como ovos, carne, leite e produtos derivados; (iii) Serviço: Os animais são importantes no auxílio e/ou na realização de tarefas/trabalhos cotidianos, constituindo elementos significativos na complementação da força de trabalho (TOSETTO; CARDOSO; FURTADO, 2013,p. 15). 
Apesar da produção animal orgânica estar presente em todo o mundo, de acordo com Willer e Lernoud (2019) as estatísticas disponíveis sobre a quantidade de animais orgânicos ainda se encontram incompletas não permitindo uma visão geral do setor. No entanto, é possível observar a partir das informações disponíveis o avanço da produção de animais orgânicos principalmente em países europeus.

Apesar de se mostrar em um bom ritmo de crescimento a participação de animais orgânicos nos países europeus permanece pequena se comparada a outras culturas, variando a participação das diferentes espécies entre 0,6\% e 5,2\%. Porcos e aves são os detentores das menores taxas, devido principalmente à insuficiência de ração orgânica para esses animais, o alto nível de investimento demandado em celeiros, destacando-se também os altos preços finais aos consumidores. Assim as maiores participações são de ovinos e bovinos, por se tratar de produções extensivas que se tornam mais fáceis para conversão orgânica (WILLER; LERNOUD, 2019).

No que se refere ao mercado de orgânicos europeu, alguns produtos de origem animal se destacam juntamente com os vegetais entre os que geram maior valor em vendas, com destaque para ovos e produtos lácteos. "Na Suécia e na Suíça, os produtos lácteos orgânicos atingem quotas de mercado de $10 \%$ ou mais. Na Dinamarca, o leite orgânico tem uma participação de mercado orgânico de 30\%."(WILLER; LERNOUD, 2019,p.244,tradução nossa)

O leite orgânico se destaca por estar presente em todos os países europeus, apresentando altos índices de crescimento, chegando a dobrar sua produção desde o ano de 2008, com o intuito de atender a grande demanda por produtos lácteos orgânicos nesses países. A produção de leite orgânico da União europeia registrada para o ano de 2017 foi de 4,4 milhões de toneladas, o que constitui cerca de 3\% da produção total (WILLER; LERNOUD, 2019).

No continente americano, os Estados Unidos da América (EUA) merece destaque especial por ser o maior mercado orgânico do mundo. As frutas e verduras continuam a ser a categoria de produtos com maior número de vendas no país chegando a registrar o valor de US\$16,5 bilhões, 5,3\% de crescimento de mercado e $14,1 \%$ do total de vendas dos EUA. Entretanto assim como na Europa os produtos orgânicos de origem animal também se mostram importantes. A categoria laticínios e ovos orgânicos formam a segunda maior de alimentos orgânicos mais vendidos nos EUA, embora tenha apresentado uma taxa modesta de crescimento 0,9\% em 2017 cerca de 6,5 bilhões de em vendas. 
No entanto pode-se observar que essa não foi uma realidade generalizada, pois, por exemplo o leite orgânico alavancou as vendas de sorvetes orgânicos em mais de $9 \%$ e queijos em quase $8 \%$ (WILLER; LERNOUD, 2019). O principal desafio que vem sendo enfrentado é a escassez de grãos orgânicos, uma vez que mesmo que os EUA seja um dos principais produtores de grãos convencionais do mundo, a produção de grãos orgânicos tais como milho e soja importantes para alimentação dos rebanhos têm sido insipientes.

Na Austrália, um dos principais países do mundo em produção orgânica, por contar com a maior extensão de terras orgânicas do mundo, os produtos de origem animal também se mostram participativos entre os principais produtos orgânicos exportados pelo país, com destaque para carne e laticínios, que juntamente com frutas, legumes e nozes, representam a maior parte do mercado interno. Alguns países são destinos certos dos produtos orgânicos da Austrália, "[...] como EUA para carne bovina, cordeiro, frutas e vegetais, Suécia para vinho orgânico, China para produtos lácteos orgânicos, Coreia do Sul para produtos de panificação e soja, e Hong Kong para ovos orgânicos."(WILLER; LERNOUD, 2019,p.295-296, tradução nossa)

No Brasil, a produção de alimentos de origem animal também se mostra importante para a economia do país, sendo bastante representativos no agronegócio nacional, como também para a alimentação da população brasileira. Essa importância é observada no relatório anual da Associação Brasileira de Proteína Animal ABPA (2018), em que por exemplo, a produção nacional de carne frango foi de 13,05 milhões de toneladas, sendo $66,9 \%$ destinada ao mercado interno, com um consumo em média 42,07 ( $\mathrm{Kg} / \mathrm{Hab})$ ficando a produção brasileira atrás apenas dos EUA. A produção de carne suína foi de 3,75 milhões de toneladas, sendo $81,5 \%$ desta produção direcionada ao mercado interno com consumo de $14,7(\mathrm{~kg} / \mathrm{hab})$.

No que diz respeito as informações da produção orgânica de origem animal brasileira, os dados ainda são reduzidos, sendo assim difícil se conformar uma realidade geral da produção nacional atualmente. De acordo com Soares, Neves e Carvalho (2014), através de levantamento realizado pela Empresa Brasileira de Pesquisa Agropecuária (EMBRAPA), a produção orgânica brasileira dos principais produtos orgânicos de origem animal do país era de 550 mil cabeças de frango, 720 mil dúzias de ovos e leite 6,8 milhões de litros de leite e 13,8 mil cabeças de gado abatidas ao ano. Quantidades consideradas ainda baixas demonstrando que esses produtos se encontram em uma fase de menor desenvolvimento no Brasil com relação aos vegetais que já são mais acessíveis aos consumidores e também com 
relação a produção de animais em sistema convencional (SOARES et al., 2011), (FIGUEIREDO; SOARES 2012).

Segundo Figueiredo e Soares (2012):

Os produtos orgânicos de origem animal mais encontrados no mercado brasileiro são a carne bovina, leite bovino e derivados, mel, ovos, carne de frango, carne suína e outros em menores proporções que são outras aves, peixes e crustáceos e coprodutos como composto orgânico, produzido a partir de resíduos das criações animais (FIGUEIREDO; SOARES, 2012, p. 4).

A baixa disponibilidade desses produtos pode ser originada devido a pequena parcela de produtores. Segundo o SEBRAE (2018) em pesquisa nacional realizada com os produtores orgânicos as taxas de produtores de produtos de origem animal são pequenos sendo registrado que do total de produtores orgânicos brasileiros apenas $9 \%$ são laticínios, 5\% carnes e $3 \%$ pescados. Um dos principais desafios encontrados para a produção se relaciona à alimentação dos animais uma vez que:

[...] Para a alimentação a limitação se dá face ao pequeno tamanho das propriedades, à escassez de rações orgânicas para suplementação alimentar durante o período de estiagem, à baixa fertilidade do solo nas áreas de pastagens, à baixa adoção da prática da adubação verde e ao clima desfavorável em determinadas épocas do ano, em algumas regiões, que no caso destes últimos também limitam os sistemas convencionais (Soares et al., 2011, p.3).

No que se refere a sanidade das criações um dos aspectos apontado entre os de principal dificuldade ao produtores Soares et al. (2011) discorre que:

Para a sanidade estão relacionados ao controle de ecto e endoparasitas sem a utilização de medicamentos químicos. Em relação ao tratamento veterinário, o objetivo principal das práticas orgânicas de criação é a prevenção de doenças. Saúde não é apenas ausência de doença, mas habilidade de resistir a infecções, ataques de parasitas e perturbações metabólicas. Desta forma, o tratamento veterinário é considerado um complemento e nunca um substituto às práticas de manejo. 0 princípio da prevenção deve ser sempre priorizado e quando houver necessidade de intervenções deve se considerar que o importante é procurar as causas e não somente combater os efeitos. Por isso, o foco deve ser a busca de métodos naturais para tratamento veterinário (SOARES et al., 2011,p.3).

Além desses entraves destaca-se a dificuldade de muitos agricultores em se adequar as normas da produção orgânica que são estabelecidas pela legislação, Lei 10831 (Brasil, 2003) e a Instrução normativa a IN 46 (Brasil,2011), principalmente no que se refere ao manejo do rebanho, que tem como princípio o uso de práticas preventivas de doenças, controle de parasitas e o plano de manejo orgânico de tudo o que está sendo realizado, uma vez que na produção orgânica de animais somente se é permitido a utilização de medicamentos químicos em casos de extrema necessidade. 
Outro limitante na realidade brasileira se relaciona a falta de assistência técnica aos produtores interessados em produzir organicamente. Um bom exemplo dessa realidade foi observado Rossi e Lemos (2013), em que de acordo com os autores a produção e comercialização de leite e derivados orgânicos ainda é reduzida no Brasil, o que pode ser reflexo, principalmente, da falta de assistência e extensão rural. De fato, parece plausível supor que se não houver a assistência técnica de extensão rural com o repasse de informações aos agricultores, auxiliando-os em aspectos gerenciais e legais de transição e manutenção para produção de orgânica, o seu crescimento no mercado será lento.

\section{Comunidades que sustentam a agricultura (CSAs)}

Dentre as estratégias que vêm sendo desenvolvidas para a valorização e comercialização de alimentos locais, Brown e Miller (2008), destacam as Comunidades que Sustentam a Agricultura (CSAs) como uma das que vêm se desenvolvendo com maior força. Realidade que pode ser explicada pela abordagem de Silva Júnior et al. (2018), uma vez que segundo os autores o modelo desenvolvido nas CSAs se torna vantajoso para ambas as partes, agricultor e consumidor.

O agricultor possui a segurança de produzir e escoar a sua produção diretamente aos coagricultores, que participam ativamente do processo produtivo e assim adquirem maior confiança com relação a procedência e qualidade dos produtos, uma vez que podem visitar a fazenda, ajudar na produção e saber o que realmente estão consumindo, além de ser uma forma muito agradável de maior interação social, o que possibilita o resgate de certos costumes perdidos com destaque ao sentimento de pertencimento de uma comunidade. Pohlmann (2015a) complementa que além de ser vantajosa aos seus membros uma CSA oferece vantagens para o cuidado com a terra, plantas e animais.

De acordo com Cone e Kakaliouras (1995), Schnel (2007), Molina e Pohlmann (2014) Henderson e Van En (2007), os primeiros movimentos de uma agricultura apoiada pela comunidade tiveram seu início no Japão por volta dos anos 1960 quando um grupo de mulheres, insatisfeitas com os alimentos processados, importados e com pesticidas, decidiram realizar acordos locais direto com os agricultores para o fornecimento de alimentos, dando assim origem aos primeiros movimentos das CSAs no mundo com o nome de teikei, palavra que em japonês significa cooperação ou parceria. Darolt (2012) estima que atualmente cerca de um quarto da população japonesa participe de algum teikei. 
Segundo Molina e PohImann (2014) o termo Community Supported Agriculture (CSA) foi desenvolvido na década de 1980, por iniciativa de dois agricultores biodinâmicos, o Suíço Jan Vander Tuin, através do projeto Topinambur na Suíça, e o alemão Trauger Groh, que também acompanhou um projeto de agricultura apoiada pela comunidade. O movimento CSA logo se popularizou em vários países da Europa, chegando nos Estados Unidos no ano de 1986, país que se destaca como um dos locais que a CSA mais se desenvolveu em todo o mundo (MARTINS, 2017).

De acordo com Ferreira Neto et al., (2015), o movimento CSA se baseia no conceito de Rudolf Steiner, de economia associativa, visando o bem comum dos membros. Dessa forma os coprodutores financiam o agricultor e recebem em troca semanalmente uma cesta de produtos, contudo o diferencial está no fato de que as pessoas não escolhem seus produtos como se estivessem fazendo compras em um supermercado, pois, ao se tornar membro de uma CSA "[...] todos compreendem a sazonalidade, as intempéries e imprevistos inerentes à atividade agrícola, aceitando as cestas e suas eventuais variações quantitativas e qualitativas com naturalidade"(FERREIRA NETO et al., 2015,p.2).

No que se refere ao acordo entre os membros apesar de haver uma certa similaridade na maneira em que as CSAs se organizam não existe uma forma única que todas devem seguir. Segundo Cone e Myhre (2000), Brown e Miller (2008) os acordos podem variar dependendo de cada organização especifica, sendo importante destacar que os membros podem contribuir com os agricultores de várias maneiras, como por exemplo, auxiliar nas colheitas e entregas de produtos, decisões financeiras, planejamento gerencial e organização de atividades comunitárias, seja como um compromisso firmado no ato da entrada do membro na CSA ou mesmo por ações voluntarias.

Após vários anos de atividade em diversos países da Europa pode-se dizer que o movimento CSA demorou um pouco a chegar no Brasil. De acordo com Molina, Santos e Figueiredo (2017), Torres (2017) somente em 2010 por meio do alemão Hermann Pohlmann. Após o desenvolvimento de várias rodas de conversa e encontros para debates sobre o assunto, no ano de 2011 foi iniciada de forma efetiva a primeira CSA do Brasil, estando ela localizada em Botucatu-SP, no bairro Demétria. A CSA herdou o nome de seu bairro Demétria e por meio do auxílio das pessoas que colaboraram com a iniciativa conseguiu ganhar força e se consolidar, demonstrando que realmente os princípios que norteiam o movimento foram introduzidos com sucesso (POHLMANN, 2015b). 
A partir de então, o movimento CSA se desenvolveu de maneira rápida e satisfatória por diversas partes do país. Segundo Martins (2017), não existe ainda um levantamento preciso sobre a quantidade de CSAs no Brasil, entretanto é notável o seu desenvolvimento e importância para a manutenção de produtores e qualidade alimentar de muitas famílias brasileiras, além de colaborar para a disseminação da agricultura orgânica e cuidados com o meio ambiente.

\title{
3.1 Produção animal e comunidades que sustentam a agricultura (CSAs)
}

Apesar do núcleo central de produção da CSA ser vegetais orgânicos, outros produtos também são frequentemente encontrados, com destaque a alguns de origem animal, tais como carne, aves domésticas e produtos lácteos (CONE \& KAKALIOURAS, 1995). A importância da integração de animais em CSAs também se apresenta dentre os fatores que influenciam a participação dos membros, conforme a pesquisa de Cone e Kakaliouras (1995) em que a possibilidade de estar em contato com animais aparece entre um dos principais motivos para a participação em uma CSA.

Além desses aspectos Schnel (2007) aponta que as CSAs vêm expandindo o seu modelo criando parcerias com produtores locais visando a diversificação de produtos:

\begin{abstract}
Por exemplo, uma fazenda que visitei oferece não apenas seus próprios produtos e ovos, mas também, por um custo adicional, sabão local, granola, mel, queijo e carne e frango empanados de capim de meia dúzia de outros produtores locais. A ideia é possibilitar que os membros confiem na CSA para uma porção maior de suas necessidades alimentares, além de ser mais fácil e conveniente para os membros comprarem o máximo possível localmente (SCHNEL, 2007,p.558).
\end{abstract}

Analisando esse mesmo aumento da variedade de alimentos produzidos em fazendas CSA Volz et al., (2016) verificaram em sua pesquisa na Europa que:

\begin{abstract}
Enquanto os vegetais têm estado no centro do modelo CSA desde a sua fase inicial (são fornecidos por $94 \%$ dos inquiridos CSAs), a variedade de produtos tende a crescer atualmente incluindo, entre outros, fruta (58\%), ovos (38\%), carne (29\%), mel (28\%), laticínios (26\%) e pão (25\%). Esta tendência mostra que os consumidores envolvidos em CSAs são dispostos a complementar seus suprimentos básicos de vegetais com todos os outros produtos que eles tinham até então comprado em lojas orgânicas, supermercados etc. Existe, portanto, um grande potencial para expandir o modelo CSA para produtos anteriormente não disponíveis através do CSA (VOLZ et al., 2016,p.120 tradução nossa).
\end{abstract}

Embora as pesquisas relacionadas a produção animal em CSAs ainda sejam reduzidas, percebe-se que esses produtos já se encontram incorporados por grande parte das fazendas, sendo importantes tanto para a disponibilização de produtos, como também para o aumento 
da diversidade ecológica dos sistemas uma vez que em sua maioria são modos alternativos de produção, tais como por exemplo a agricultura orgânica e de base ecológica. Acrescenta-se ainda a capacidade da criação de animais em promover maior interação social entre as pessoas, que se envolvem nas tarefas diárias de alimentação e manejo (GORMAN, 2018).

\section{Metodologia}

Com base nos objetivos traçados, este trabalho foi considerado como um estudo descritivo e exploratório. De acordo com Gil (2008), pesquisas exploratórias possibilitam a aproximação e visão geral do assunto pesquisado. As pesquisas descritivas segundo Gil (2010), são aquelas que tem como objetivo a descrição das características da população pesquisada, podendo também ser utilizada para identificar relações entre variáveis.

Com base nos procedimentos técnicos utilizados para delinear o modelo conceitual e operacional a pesquisa se classifica como um estudo de caso, com uma abordagem quantitativa, tendo como público alvo 16 produtores pertencentes do assentamento Nova Camapuã de São Sebastião-DF, os quais desenvolvem diversas atividades agrícolas, e vêm demostrado interesse de implementar melhorias quanto a avanços na produção orgânica por meio de sistemas integrados de produção animal e vegetal em suas propriedades. Além disso também buscam alternativas que auxiliem para a viabilização de suas atividades através da busca de organizações e sistemas produtivos que auxiliem na valorização e escoamento de seus produtos. Dessa forma, justifica-se a escolha da comunidade como participante da pesquisa, uma vez que seus anseios se demostram compatíveis ao movimento Comunidades que Sustentam a Agricultura (CSAs)

O instrumento utilizado para a coleta de dados foi um questionário survey, sendo neste abordadas todas as dimensões levantadas no objetivo da pesquisa. Por se tratar de um número de propriedades acessível para a realização de visitas junto a todos os produtores para a aplicação dos questionários o único critério adotado para a seleção dos participantes foi: Agricultores que se disponibilizaram a participar do estudo.

O tratamento e análise dos dados, foi realizado por meio de análises estatísticas e de conteúdo. Para a realização da presente análise, inicialmente, foram aplicados cálculos descritivos tais como média, desvio-padrão e coeficiente de variação. No que se refere ao tratamento e análise dos dados qualitativos, as respostas obtidas por meio das questões abertas foram agrupadas em categorias temáticas e tratadas por meio da análise de conteúdo. 
Para verificar se a frequência absoluta observada de uma variável categórica é significativamente diferente da distribuição de frequência absoluta esperada foi aplicado o teste não paramétrico de Qui-quadrado $\left(\mathrm{Q}^{2}\right)$. Desta forma, com este teste foi possível avaliar quantitativamente a relação entre o resultado observado no estudo e a sua distribuição esperada para o fenômeno. Todas as análises estatísticas foram realizadas com o auxílio do software Excel, versão 2016.

\section{Resultados e discussão}

5.1 Perfil da produção, integração animal, comunidades que sustentam a agricultura (CSA)

No que se refere às áreas das propriedades, elas variam de 4 a 6 hectares (ha), havendo maior predominância daquelas com 4ha, são 10 propriedades, sendo esses um resultado significativo, conforme o teste do qui-quadrado $\left(Q^{2}\right)$. Dessa forma, é possível notar que, de maneira geral, essa realidade se assemelha aos resultados do censo agropecuário (IBGE, 2017), em que de acordo com o mesmo existe a predominância de pequenas propriedades agropecuárias no Distrito Federal, com áreas que variam de 0 a 10ha, demostrando ser uma característica da região. Observa-se ainda que os agricultores, apesar das pequenas áreas, destinam uma parcela das propriedades exclusivamente para a produção animal com áreas que variam de 0,05 ha a 2,50ha.

Ainda quanto as áreas destinadas para produção animal, percebe-se que, de maneira geral, elas correspondem a uma pequena fração da propriedade. Conforme verificado os agricultores destinam apenas em média 13,20ha da área total do assentamento 70,39 para criar animais. Os principais tipos de produção encontrados são, milho, frutas e mandioca, presentes em todas as 16 propriedades, como também os produtos, leguminosas presentes em 15 propriedades, ovos (14), carne (14) e cana (10) representativos de acordo com o teste do qui-quadrado $\left(\mathrm{Q}^{2}\right)$. Em um panorama geral do assentamento, é possível observar um certo equilíbrio quanto as produções de origem animal e vegetal presentes nas propriedades, característica importante para o desenvolvimento de sistemas de produção orgânicos conforme (FIGUEIREDO; SOARES, 2012).

A produção de origem animal no assentamento se caracteriza pela criação de pequenos animais, o que pode ser atribuído as pequenas áreas das propriedades, como também pela caraterística produtiva do Distrito Federal. A maioria dos estabelecimentos se 
dedicam a produção de aves (ovos) (14), aves (carne) (14) e suínos (10). Esses resultados foram significativos segundo o teste de qui-quadrado $\left(Q^{2}\right)$, com destaque ainda maior para as aves que apresentam o maior número médio de animais por propriedade, aves para a produção de ovos são 20 animais e aves para carne a média é de 13,6 animais.

Além de se apresentar como uma importante fonte de renda, a produção animal na comunidade é desenvolvida com um baixo custo aos produtores, sendo gasto médio mensal de apenas $\mathrm{R} \$ 149,37$ por propriedade. O que torna ainda mais interessante para os produtores realizarem a manutenção da produção animal, além da contribuição financeira, é, também, a possibilidade de destinar parte da produção para o próprio consumo com um baixo custo, considerando-se a quantidade de animais criados e a variedade de produtos gerados a partir dos mesmos.

Apesar do assentamento apresentar uma boa variedade de produtos, tanto vegetais como de origem animal, uma das principais dificuldades encontradas no âmbito da agricultura familiar brasileira se encontra na comercialização de seus produtos. Nessa perspectiva, o desenvolvimento de estratégias e arranjos que possibilitem uma maior facilidade de escoamento a preços justos é de suma importância, devendo englobar, principalmente, o encurtamento das relações de confiança entre produtores e consumidores através de vendas diretas, quando se destacam as CSAs como importantes inciativas, que vêm se desenvolvendo recentemente no Brasil.

As CSAs, por sua vez, se baseiam na parceria direta entre consumidores e produtores, garantindo uma alimentação saudável à população e segurança aos agricultores. Conforme exposto na tabela 1 percebe-se que a maioria dos produtores pesquisados (11) ainda não tinham conhecimento desse modelo até a realização desta pesquisa sobre o movimento CSA, o que pode ser explicado pelo fato de este ser ainda relativamente novo no Brasil. Contudo, após ser explicado e apresentado o modelo de funcionamento das CSAs, percebeu-se que a grande maioria (14), acredita que a formação de uma CSA atenderia às suas necessidades e dessa forma teriam interesse em participar do movimento, sendo esse dado significativo de acordo com o teste de qui-quadrado $\left(Q^{2}\right)$.

Todos os 14 produtores que possuem interesse em formar uma CSA acreditam que é possível ofertar produtos de origem animal. Acrescenta-se, também, que $71,4 \%$ (10) desses produtores interessados em formar uma CSA (10) possui a percepção de ser possível ofertar produtos de origem animal como parte da quota nas entregas semanais de produtos realizadas no modelo CSA. Apesar de pesquisas sobre produção animal em CSA ainda não 
serem tão difundidas na literatura, esses dados apontam na mesma direção daqueles encontrados por Volz et al. (2016), que, através de pesquisas realizadas em diversos países da Europa, verificou a tendência por uma maior diversificação dos produtos nas CSAs, dentre os quais aparecem os de origem animal, uma vez que, até então o movimento era baseado, principalmente, em produtos vegetais.

A formação de uma CSA e a oferta de produtos de origem animal aos membros pode assegurar uma ótima oportunidade aos produtores do assentamento Nova Camapuã-DF, uma vez que são produzidos diversos produtos de origem animal que fazem parte do cardápio da maioria dos brasileiros. Isso pode gerar maiores rendas e segurança aos produtores. Até mesmo podem diversificar e aumentar a sua produção, uma vez que, conforme Estevam et al. (2018), muitas vezes os produtores têm receio de investir nos seus negócios por insegurança em relação ao mercado e de que não dê o resultado esperado.

De maneira geral, torna-se também vantajoso para os consumidores, que terão conhecimento sobre a origem e o modo de produção de seus alimentos, fato que ganha cada dia mais importância conforme aponta Darolt et al. (2016). Acrescenta-se ainda a maior variabilidade de produtos disponíveis e o fato de que a presença de animais está entre os principais critérios para a participação das pessoas no movimento CSA (CONE; KAKALIOURAS, 1995).

Tabela 1 - Percepção dos produtores do assentamento Nova Camapuã-DF sobre sistemas integrados de produção, em CSA.

\begin{tabular}{|c|c|c|c|}
\hline & Descrição & Quantidade de Produtores & (\%) \\
\hline \multirow{13}{*}{$\begin{array}{l}\text { Comunidades } \\
\text { que Sustentam } \\
\text { a Agricultura } \\
\text { (CSAs) }\end{array}$} & \multicolumn{3}{|l|}{ Conhecimento sobre CSA } \\
\hline & Não & 11 & $68,75 \%$ \\
\hline & Sim & 5 & $31,25 \%$ \\
\hline & \multicolumn{3}{|c|}{ Interesse em Participar Após Adquirir Conhecimento } \\
\hline & Não & 2 & $12,50 \%$ \\
\hline & $\mathrm{Sim}^{*}$ & 14 & $87,50 \%$ \\
\hline & \multicolumn{3}{|c|}{ Possibilidade da Oferta de Produtos de Origem Animal Caso Forme uma CSA } \\
\hline & NR & 2 & - \\
\hline & $\mathrm{Sim}^{*}$ & 14 & $100 \%$ \\
\hline & \multicolumn{3}{|c|}{ Escoamento dos Produtos de Origem Animal } \\
\hline & Adicionais & 4 & $28,57 \%$ \\
\hline & $\begin{array}{l}\text { Parte da Quota de produtos } \\
\text { entregues semanalmente* }\end{array}$ & 10 & $71,42 \%$ \\
\hline & NR & 2 & - \\
\hline
\end{tabular}

$(*)$ Significativo pelo teste de qui-quadrado $\left(Q^{2}\right)$ com nível de probabilidade de $5 \%$. Fonte: Dados da Pesquisa com produtores da Comunidade Nova Camapuã-DF

Os produtores já se mostram adeptos de meios de comercialização diretamente, por meio de venda em feira, encomendas, e clientes que vão comprar em suas propriedades. 0 
fato de os produtores já possuírem clientes que realizam encomendas e estão dispostos até mesmo a ir comprar alimentos nas propriedades traz indícios de que em caso de optarem por formar uma CSA, já teriam possíveis membros dispostos a participar. Isto porque esses consumidores já conhecem os produtos desses agricultores e os aprovam como de qualidade conforme a fala de um dos produtores que diz, [...] "encomenda, o pessoal quando sabe que estou vendendo compra tudo".

Nesse contexto também se mostra interessante, a alta procura de alimentos orgânicos de origem animal, o que contrasta significativamente com os dados apresentados anteriormente na tabela 1 , no que diz respeito à percepção positiva dos produtores quanto a possibilidade da oferta de produtos de origem animal em CSA. Acrescenta-se que a procura por produtos orgânicos de origem animal apresentada nesta pesquisa, muito se assemelha aos relatos de (WILLER E LERNOUD, 2019), (FIGUEIREDO; SOARES, 2012).

Outro ponto relevante dos sistemas de produção integrados, verificado no assentamento Nova Camapuã que pode favorecer substancialmente para a produção orgânica, é o aproveitamento de resíduos. A maioria dos produtores (12) não necessitam comprar todos os insumos necessários para a sua produção/criação, o que diminui os custos produtivos e consequentemente possibilita melhoria nos ganhos econômicos.

A diminuição da necessidade da compra de insumos se mostra estreitamente ligada ao aproveitamento de resíduos, ao se observar que 15 dos produtores pesquisados relataram realizar o aproveitamento de resíduos, entre as produções de origem animal e vegetal, sendo esses dados significativos, de acordo com o teste de qui-quadrado $\left(Q^{2}\right)$. Diante dessas constatações percebe-se semelhanças aos achados de Tosetto, Cardoso e Furtado (2013); Silva et al. (2018); Trecenti et al. (2008) sobre sistemas integrados de produção.

\subsection{Capital social, aprendizado e arranjos institucionais}

O capital social se destaca como peça chave do bom funcionamento de sistemas de comercialização em cadeias curtas, ao qual se enquadra o movimento CSA (FERREIRA NETO et al., 2015), (POHLMANN, 2015), (TIBURTINO et al., 2018), (FIELDHOUSE, 1995), (DAROLT et al., 2016), (HELENA et al., 2017), (BRANCHER, 2004). Nesse sentido, a percepção dos produtores em relação ao capital social apresenta boas médias, estando todas acima da nota 7, e com um baixo desvio padrão, o que revela homogeneidade nas respostas, demostrando dessa maneira ser um consenso em todo o assentamento. 
Os produtores demostram facilidade em desenvolver relações sociais, uma vez que conforme demostrado possuem confiança nas pessoas com as quais tem contato na realização de atividades nota $(7,56)$, mantem relações próximas com membros de organizações parceiras $(7,19)$, buscam solucionar problemas e buscar melhorias de maneira conjunta desenvolvendo uma boa comunicação. Essa afirmação é comprovada pelo fato de presarem pela comunicação por meio de encontros e reuniões $(8,38)$, pelas expectativas de relações duradouras $(8,19)$, terem modificado a forma de produzir em função dos projetos conjuntos com organizações parceiras $(7,56)$. Além destes, ainda informaram que conseguem falar a mesma linguagem $(7,50)$, entendem que a solução conjunta de problemas é importante (8), além de partilharem da mesma visão de agricultura e condições de produção que os parceiros $(7,13)$. Dessa forma, verificou-se, a partir das respostas dos produtores, que ao se pensar na formação de uma CSA os níveis do capital social apresentados são favoráveis.

As pessoas envolvidas no trabalho das propriedades são em sua maioria, o produtor e sua família em $81,25 \%$ dos casos, sendo esse dado significativo de acordo com o teste de quiquadrado $\left(\mathrm{Q}^{2}\right)$. O que confirma a forte presença da agricultura familiar no assentamento e a importância da união familiar para os produtores, tanto no aspecto social de permanecerem reunidos, como também no que se refere à força de trabalho para a realização das atividades diárias.

Outro ponto relevante demonstrado pelos produtores diz respeito à influência positiva da criação e o manejo de animais para o fortalecimento das relações sociais, que podem ser favoráveis à formação de uma CSA. Todos os 16 produtores pesquisados possuem essa percepção positiva, reforçando ainda mais a importância de sistemas produtivos integrados, se assemelhando aos resultados de Gorman (2018), Dias et al. (2009), que verificaram avanços das relações sociais através da criação e o manejo diário de animais.

\subsection{Políticas públicas, valoração de produtos e análise socioeconômica}

Ao se analisar o acesso dos produtores a políticas públicas deve-se primeiramente destacar a importância destas para a agricultura familiar, o que tornou esse um dos temas mais debatidos na literatura brasileira. Essa relação foi alavancada principalmente em decorrência do ideário produtivo inserido pelas políticas públicas, nas décadas de 1960 e 1970, que, segundo Andrade (1998), Guanziroli et al. (2001), Souza (2011), Mattei (2014), 
contribuíram para a formação de uma classe fragilizada de agricultores familiares e para um aumento das disparidades com os grandes produtores.

Conforme os resultados da pesquisa, os produtores do assentamento Nova Camapuã não contam com praticamente nenhum apoio no que diz respeito a políticas públicas. Todos os 16 produtores pesquisados relataram não ter acesso a crédito, e (14) não participam de programas governamentais, sendo esse dado significativo de acordo com o teste de quiquadrado $\left(Q^{2}\right)$.

Acrescenta-se, ainda, a falta de acesso ao crédito indispensável para a realização de investimentos produtivos e estruturais nas propriedades. Realidade desfavorável, ao se analisar que o acesso ao crédito sempre foi um dos principais anseios da classe de produtores familiares brasileiros, conforme destaca Bianchini (2015), ainda sendo apontado por Paiva (1969), Sampaio (2010), Guanziroli et al. (2001), como o principal motivo para as dificuldades enfrentadas para o desenvolvimento da agricultura familiar.

Quanto à análise econômica percebe-se que, de maneira geral, a maior parte dos produtores possuem uma renda mensal de até $\mathrm{R} \$ 998,00$, valor correspondente ao saláriomínimo da época, estando essa concentração presente nos três tipos de renda levantados. Estas são a renda de atividades agrícolas e pecuárias (75\%), a renda de atividades não agrícolas (50\%) e a renda geral que engloba a soma dos dois tipos de renda citados anteriormente $81,25 \%$, sendo todos esses dados significativos de acordo com o teste de qui-quadrado $\left(Q^{2}\right)$.

O fato de a maior parte dos produtores possuírem suas rendas, derivadas de atividades agrícolas e não agrícolas, na faixa de até $\mathrm{R} \$ 998,00$ e, também, serem a maioria pertencentes a essa mesma classe para a renda geral, demostra que as rendas auferidas em atividades agrícolas e não agrícolas, apesar de fazerem parte da classe de até $R \$ 998,00$, são inferiores a ela, uma vez que quando somadas não ultrapassam o valor de um salário-mínimo mensal.

Essa realidade se assemelha a que é amplamente discutida sobre a agricultura familiar brasileira. Conforme Mattei (2014), Abramovay (1990), Mundo Neto e Souza Filho (2005), isso desperta para a necessidade de ações que possibilitem aos produtores a melhoria de suas condições, principalmente se pensando que dependem dessa renda para a manutenção de suas famílias, que em média são compostas por 3,5 pessoas. Destaca-se ainda que esse contexto pode ser originário, principalmente, da falta de acesso ao crédito. 
Nesse contexto, percebe-se que apesar dos produtores identificarem o quanto a agricultura orgânica se encontra valorizada, eles têm se deparado principalmente nos aspectos financeiros para a realização de investimentos em suas propriedades.

Dessa forma percebe-se que o modelo CSA poderia auxiliar os produtores nesse contexto, uma vez que nele são calculados todos os gastos necessários para a produção e um salário digno ao agricultor, conforme destacam (TORUNSKY et al., 2015) e (POHLMANN, 2015a).

\section{Considerações finais}

Os sistemas produtivos integrados podem trazer benefícios no que diz respeito ao desenvolvimento da produção orgânica junto à agricultores familiares, assim como para a formação de modelos comerciais que tragam melhores resultados, através da aproximação entre produtores e consumidores.

As CSAs, modelo de escoamento de produtos, desenvolvido por meio da parcerias entre produtores e consumidores, se adaptam à realidade dos produtores familiares do assentamento Nova Camapuã-DF. A criação de animais estimulou a elaboração de estratégias para a integração das produções animal e vegetal, o que apresentou inúmeros benefícios, como por exemplo, o reaproveitamento de resíduos, e o estímulo à produção orgânica. Além disso apresentou-se como uma importante fonte de renda, por meio da venda dos produtos de origem animal, principalmente ovos e aves (carne), que segundo os produtores são constantemente procurados por meio de encomendas.

Houve a percepção positiva, do ponto de vista dos produtores, quanto à formação de CSAs para melhorias na realidade vivenciada no assentamento, e, também, sobre a importância da presença de animais nesse modelo. Outro ponto positivo verificado foi a possibilidade de oferta de produtos de origem animal, estimulada primordialmente pela procura dos consumidores, o que enriquece a importância de sistemas integrados, principalmente ao se analisar o modelo CSA que até então era formado principalmente por produtos vegetais.

Ao se analisar a percepção dos produtores quanto ao capital social, peça chave do funcionamento de uma CSA, identificou-se que, de maneira geral, os índices apresentados foram favoráveis tanto para as relações sociais internas ao assentamento como também com parceiros externos. Destaca-se que o trabalho desenvolvido nas propriedades em sua maioria 
se restringe a força de trabalho familiar, tendo a criação de animais, na visão dos agricultores, influências positivas quanto ao fortalecimento dessas relações sociais.

Ao avaliar o acesso dos produtores a políticas públicas, percebeu-se que esse é um dos principais empecilhos para a realização de melhorias produtivas e estruturais em suas propriedades, principalmente devido à falta de acesso ao crédito, indispensável ao se pensar na realidade dos agricultores familiares brasileiros. $O$ que não é diferente no assentamento Nova Camapuã-DF, uma vez a maior parte das rendas auferidas mensalmente estão na faixa de até $\mathrm{R} \$ 998,00$ reais/mês. Esta realidade pode ser apontada como sendo o principal motivo para a necessidade dos produtores se revezarem entre atividades agrícolas e não agrícolas

Dessa forma, percebe-se que o modelo CSA pode auxiliar os produtores familiares no que se refere à dificuldade financeira para realização de investimentos produtivos, uma vez que nesse modelo são calculados todos os gastos necessários para a produção, mais os ganhos que possibilitem um salário digno ao agricultor.

Em suma, o presente estudo traz contribuições no que se refere à integração de animais para o desenvolvimento da produção orgânica e ao modelo CSA, uma vez que este ainda é um tema pouco explorado na literatura, principalmente com relação à participação dos produtos de origem animal em CSAs. E, também, contribui de forma positiva para uma maior integração de animais nos sistemas produtivos dos estabelecimentos familiares e para a melhoria nas relações sociais, que são de suma importância para o bom funcionamento do modelo CSA.

\section{Referências}

ABPA, A. B. DE P. A. Relatório anual 2018. 2018.

ABRAMOVAY, R. De Camponeses a Agricultores Paradigmas do capitalismo Agrário em Questão. Campinas, 1990.

ABREU, L.; BELLON, S.; BRANDEBURG, A.; et al. Relações entre agricultura orgânica e agroecologia: desafios atuais em torno dos princípios da agroecologia. Desenvolvimento e Meio Ambiente, v. 26, p. 143-160, 2012.

ALTIERI, M. A. Agroecologia: a dinâmica produtiva da agricultura sustentável. 4.ed ed. Porto Alegre, 2004.

ANDRADE, J. G. Introdução a Administração Rural. Lavras: FAEPE /UFLA, 106 p., 1998.

ASSIS, R. L. DE; ROMEIRO, A. R. Agroecologia e agricultura orgânica: controvérsias e tendências. Desenvolvimento e Meio Ambiente, v. 6, n. 6, p. 67-80, 2002. 
BAINBRIDGE, M. L.; EGOLF, E.; BARLOW, J. W.; et al. Milk from cows grazing on cool-season pastures provides an enhanced profile of bioactive fatty acids compared to those grazed on a monoculture of pearl millet. Food Chemistry, v. 217, p. 750-755, 2017.

BIANCHINI, V. Vinte anos do PRONAF, 1995 - 2015: avanços e desafios. Brasília, 2015.

BRANCHER, P. C. Importância da Certificação na definição dos preços de produtos orgânicos praticados na Região Metropolitana de Curitiba. Congresso da SOBER. Anais.... v. XLII, p.1128, CURITIBA, 2004.

BROWN, C.; MILLER, S. The Impacts of Local Markets: A Review of Research on Farmers Markets and Comunity Supported Agriculture (CSA). Agricultural and Applied Economics Association, v. 90, n. 5, p. 1296-1302, 2008.

CONE, C. A.; KAKALIOURAS, A. Community Supported Agriculture: Building Moral Community or an Alternative Consumer Choice by. p. 28-31, 1995.

; MYHRE, A. Community-Supported Agriculture: A Sustainable Alternative to Industrial Agriculture? Human Organization, v. 59, n. 2, p. 187-197, 2000.

DAROLT, M. R.; LAMINE, C.; BRANDENBURG, A.; ALENCAR, M. DE C. F.; ABREU, L. S. REDES ALIMENTARES ALTERNATIVAS E NOVAS RELAÇÕES PRODUÇÃO-CONSUMO NA FRANÇA E NO BRASIL. Ambiente \& Sociedade, v. XIX, n. 1414-753X, p. 1-22, Campinas, 2016.

DIAS, J.; SOUZA, J. R. DE; LEITE, R. G.; et al. Introdução de animais em sistemas de produção de hotaliçs organicas na Região Serrana Fluminense. Agriculturas, v. 6, p. 36-40, 2009.

ESTEVAM, D. DE O.; SALVARO, G. J.; SANTOS, V. J. D. DOS. Os desafios da inserção formal de produtos da agricultura familiar no mercado 1. Redes- Universidade de Santa Cruz do Sul, v. 23, n. 1, p. 262-281, Santa Cruz do Sul, 2018.

FERREIRA NETO, D. N.; AMORIM, J. O. DE L.; MOLINA, A. DE A.; TORUNSKY, F. Financiamento da Produção Agroecologica a partir do modelo de CSA (Comunidade que Sustenta a Agricultura):um Panorama no estado de São Paulo. IX CONGRESSO BRASILEIRO DE AGROECOLOGIA. Anais.... v. 10, Belém/PA, 2015.

FIELDHOUSE, P. Community Shared Agriculture. SUMMER, v. 13, p. 43-47, 1995.

FIGUEIREDO; E. A. P. DE; SOARES, J. P. G. Sistemas orgânicos de produção animal: dimensões técnicas e econômicas. Anais da 49a Reunião Anual da Sociedade Brasileira de Zootecnia A produção animal no mundo em transformação. Anais.... p.1-3, 2012.

GIL, A. C. Métodos e Técnicas de Pesquisa Social. 6a Edição ed. São Paulo, 2008.

Como Elaborar Projetos de Pesquisa. 5. ed. São Paulo: Atlas, 2010.

GORMAN, R. Human-livestock relationships and community supported agriculture (CSA) in the UK. Journal of Rural Studies, v. 61, n. April, p. 175-183, 2018.

GUANZIROLI, C. E. Agricultura Familiar e Reforma Agrária no século XXI. Rio de Janeiro: Garamond, 2001.

HATANAKA, M.; BAIN, C.; BUSCH, L. Third-party certi W cation in the global agrifood system. Food Policy, v. 30, p. 354-369, 2005.

HELENA, R.; SAMBUICHI, R.; MOURA, I. F. DE; MATTOS, L. M. DE. A Política Nacional de Agroecologia e Produção Orgânica no Brasil: uma trajetória de luta pelo desenvolvimento rural sustentável. Brasília: Ipea, 2017. 
HENDERSON, E; VAN EN, R. Sharing the harvest: a citizen's guide to community supported agriculture. 2. ed. Vermont: Chelsea Green Publishing Co., 2007.

IBGE. Resultados definitivos: Distrito Federal. Disponível em: <https://censos.ibge.gov.br/agro/2017/templates/censo_agro/resultadosagro/pdf/df.pdf>. Acesso em: 4 Dez. 2019.

LIANG, D.; SUN, F.; WATTIAUX, M. A.; et al. Effect of feeding strategies and cropping systems on greenhouse gas emission from Wisconsin certified organic dairy farms. Journal of Dairy Science, v. 100, n. 7, p. 5957-5973, 2017.

MANDOLESI, S.; NICHOLAS, P.; NASPETTI, S.; ZANOLI, R. Identifying viewpoints on innovation in low-input and organic dairy supply chains: A Q-methodological study. Food Policy, v. 54, p. 25-34, 2015.

MARTINS, A. L. B. AGRICULTURA APOIADA PELA COMUNIDADE OU COMUNIDADE APOIADA PELA AGRICULTURA? A relação campo-cidade pela ética da solidariedade. 2017. 413f. Tese (Doutorado em Geografia) - Universidade Federal Fluminense, Niterói, 2017.

MOLINA, A. DE A.; POHLMANN, H. AGRICULTURA BIODINÂMICA E COMMUNITY SUPPORTED AGRICULTURE- CSA. São Paulo, 2014.

; SANTOS, W.; FIGUEIREDO, C. V. Métodos de Comercialização pela economia associativa? a importância da CSA. In: Valeria Paschoal; Ana Beatriz Baptistela; Neiva dos Santos Souza. (Org.). Livro Nutrição Funcional \& Sustentabilidade: alimentando um mundo saudável. 1 ed. p. 293-316, São Paulo: 2017.

MATTEI, L. O. PAPEL E A IMPORTÂNCIA DA AGRICULTURA FAMILIAR NO DESENVOLVIMENTO RURAL BRASILEIRO CONTEMPORÂNEO. The role and the importance of the Family Farm in the contemporary Brazilian rural development. Revista Econômica do Nordeste, v. 45, p. 83-91, 2014.

MUNDO NETO, M; SOUZA FILHO, H. M. Problemas do crédito rural sob a ótica da Nova Economia Institucional. Revista de Ciências Gerenciais, v. 9, n. 11, p. 92-99, 2005.

NICHOLAS, P. K.; MANDOLESI, S.; NASPETTI, S.; ZANOLI, R. Innovations in low input and organic dairy supply chains-What is acceptable in Europe? Journal of Dairy Science, v. 97, n. 2, p. 1157-1167, 2014.

PAIVA, R. M. Apreciação geral da sobre o comportamento agricultura brasileira. Revista de Administração Pública, Rio de Janeiro, v. 3, n. 1, p. 55-117, 1969.

POHLMANN, H. Comunidade que Sustenta a Agricultura. $1^{\circ}$ JORNAL CSA BRASIL, p. 1-4, 2015a. Disponível em: <http://www.csabrasil.org/csa/category/jornal/>. Acesso em: 20 de Mar.2018.

. O ARTISTA COMO MEDIADOR SOCIAL: CSA COMO EXERCÍCIO DA ESCULTURA SOCIAL. $24^{\circ}$ Encontro da ANPAP COMPARTILHAMENTOS NA ARTE: REDES E CONEXÕES. Anais.... Santa Maria, RS, p.3776-3785, 2015b.

REY, R. New Challenges and Opportunities for Mountain Agri-Food Economy in South Eastern Europe. A Scenario for Efficient and Sustainable Use of Mountain Product Based on the Family Farm, in an Innovative, Adapted Cooperative Associative System - Horizon 2040. Procedia Economics and Finance, v. 22, n. November 2014, p. 723-732, 2015. 
RIBEIRO, M. N.; ARANDAS, J. K. G. Importância de sistemas de produção de baixo impacto ambiental na conservação de recursos zoogenéticos. Rev. Cient. Prod. Anim., v. 20, p. 7181, 2018.

ROSSI, G. A. M.; LEMOS, P. DE P. L. Comparação da produção animal entre os sistemas orgânico e o convencional. Revista de Educação Continuada em Medicina Veterinária e Zootecnia do CRMV - SP, v. 11, n. 1, p. 6-13, 2013.

SAMPAIO, S. V. Questão agrária: novas relações, velhos problemas. Anais... XVI Encontro Nacional dos Geógrafos, Porto Alegre, 2010.

SCHNEL, S. S. M. FOOD WITH A FARMER 'S FACE: COMMUNITY-SUPPORTED AGRICULTURE IN THE UNITED. Geographical Review, v. 97, n. 4, p. 550-564, 2007.

SEBRAE, S. B. DE A. ÀS M. E P. E. Pesquisa com produtores orgânicos 2018. Disponível em: <https://m.sebrae.com.br/Sebrae/Portal Sebrae/Anexos/Pesquisa com Produtores Orgânicos 2018 Sebrae_21.6.2018.pdf>. Acesso em: 25 de Fev. 2019.

SILVA, P. T. P.; FERNANDES, B. C.; FERREIRA, E. L.; BEVILACQUA, P. D. Integração animal e diversidade de alimentos oriundos de quintais agroecológicos em propriedades familiares da Zona da Mata Mineira. VI CONGRESSO LATINO-AMERICANO X CONGRESSO BRASILEIRO V SEMINÁRIO DO DF E ENTORNO. Anais.... v. 13, p.1-6, Brasília, 2018.

SILVA JÚNIOR, E. C. DA; SANTANA, G. S.; MUÑOZ, M. S. G.; et al. Comércio justo e gestão ambiental para a sustentabilidade: o caso de uma comunidade que sustenta a agricultura (csa). Cadernos de Ciência \& Tecnologia, v. 35, p. 11-36, 2018.

SOARES, J. P. G.; AROEIRA, L. J. M.; FONSECA, A. H. DA; et al. Produção orgânica de leite: desafios e perspectivas. In: S. G. Editora (Ed.); III SIMLEITE; III SIMPÓSIO NACIONAL DE BOVINOCULTURA LEITEIRA; I SIMPÓSIO INTERNACIONAL DE BOVINOCULTURA LEITEIRA. Anais.... p.13-43, Viçosa, 2011.

SOARES, J. P. G.; NEVES, D. L.; CARVALHO, J. M. DE. Produção de carne bovina em sistema orgânico. In: M. A. A. F. (Org. Oliveira, R. L.; BARBOSA (Ed.); Bovinocultura de corte: desafios e tecnologias. $2^{\text {a }}$ ed., p.701-725, Salvador: EDUFBA, 2014.

SOUZA, L. R. D. S. A modernização conservadora da agricultura brasileira, agricultura familiar, agroecologia e pluriatividade: diferentes óticas de entendimento e de construção do espaço rural brasileiro. cuad. desarro. rural, v. 67, p. 231-249, 2011.

TORRES, CAMILA LOMBARDI. Comunidade que Sustenta a Agricultura, Universidade de Brasília, 2017.

TORUNSKY, FL.; FERREIRANETO, D. N.; AMORIM, J. O. DE L. CSA: Comunidade que Sustenta Agricultura, uma experiência em São Carlos. IX CONGRESSO BRASILEIRO DE AGROECOLOGIA. Anais.... v. 10, 2015.

TOSETTO, E. M.; CARDOSO, I. M.; FURTADO, S. D. C. A importância dos animais nas propriedades familiares rurais agroecológicas. Revista Brasileira de Agroecologia, v. 8, n. 3, p. 12-25, 2013.

TRECENTI, R.; OLIVEIRA, M. C. de; HASS, G. Integração lavoura-pecuária silvicultura; Boletim Técnico Ministério da Agricultura, Pecuária e Abastecimento. Secretaria de Desenvolvimento Agropecuário e Cooperativismo - MAPA/SDC; p. 54, Brasília, 2008.

VOLZ, P.; WECKENBROCK, P.; NICOLAS, C.; JOCELYN, P.; DEZSÉNY, Z. Overview of Community Supported Agriculture in Europe. $1^{\circ}$ ed. European CSA Research Group, France, 2016. 
WILLER, H.; LERNOUD, J. The World of Organic Agriculture. Statistics and Emerging Trends 2019. Research Institute of Organic Agriculture (FiBL), Frick and IFOAM - Organics International, Bonn, 2019. 